ally driven controls actuated by a single simple joystick.

In its work on chemical engineering the laboratory has been concerned with computer control of chemical plant. A piece of demonstration equipment is being built and university research workers and men from industry will be able to use this as a means of testing theories of optimization to be applied to real plants.

Among the work on mineral science is a programme for the detailed study of froth flotation. The work consists of a study of the physical chemistry of the "wettability" of the surfaces of mineral granules, and an attempt is being made to link the chemical structure of the materials with their physical behaviour as small particles. The practical incentive of this work is the recent recognition that Cornish tin might yet be worth mining-a process in which the separation of ore from dross must be carried out by flotation.

\section{No Freeze in Antarctica}

Antarctica is no longer the desolate and hostile continent that Admiral Byrd and his fellow explorers battled with over thirty years ago. In 1966 there were 41 stations operating in Antarctica and sub-Antarctica and for ten years nations have been co-operating in continuous research on the continent. During the coming Antarctic summer the United States alone is sponsoring some 150 scientists undertaking 50 field projects. About 35 scientists also work round the year on the Antarctic research vessel Eltanin that carries out a multi-discipline research programme in the Southern Oceans. The National Science Foundation, the sponsoring body, has granted approximately 7.6 million dollars this year for Antarctic research. One of the most extensive Antarctic surveys ever to be undertaken by the United States will be a 1,500 mile air-supported traverse of the coast of Marie Byrd Land, beginning in November and lasting until midFebruary; twenty scientists will study the geology and geophysics of the area and conduct botanical and topographic surveys.

Other programmes of research include investigations of fungi, algae and lichens in the Antarctic dry valleys, studies of the Earth's gravitational and magnetic fields, deep core drilling to penetrate the ice cap at Byrd Station, and the orientation processes of the Adélie penguin. A group from the University of Oklahoma will study their colleagues who have spent the winter at the South Pole, often isolated for ten months at a time, to learn how men adapt to extreme environments, both on Earth and in outer space.

\section{Food and Drink Analysis}

Those who feel that modern methods of food production have sacrificed taste and nutritional value to profitability will welcome research which is to be undertaken at the Laboratory of the Government Chemist (Report of the Government Chemist 1965, H.M.S.O., 15s.). A programme in collaboration with the newly formed Committee on Food Composition will examine the nutritional composition of common foods, and will compare old and new methods of production. Since 1957 a voluntary flour sampling scheme has been in operation, and the latest results indicate that the nutritional value of the flours examined has been well maintained. Another new development at the laboratory is the creation of a group to undertake basic research into chemical analysis. This group will have a measure of independence from the day to day demands of analytical work to which the laboratory is committed, and will increase the productivity of the laboratory by improving and automating analytical procedures.

For the rest, the report covers familiar ground. Improved methods are now available for the determination of toxic substances in industrial atmospheres, and for the determination of detergent residues in sewage effluents by thin layer chromatography. This work has shown that mixtures of the new polyethylene liquid detergents and the older powder form cause greater foaming of rivers when mixed together than when separately present. Radiochemical investigation of the sand filters commonly used in waterworks has led to the satisfactory conclusion that in addition to removing manganese, these filters act as effective scavengers in removing some of the undesirable radio-nuclides which enter the water through nuclear fall-out. A new method using gas chromatography has been developed for the analysis of Scotch whisky. The wholesomeness of modern food may be in doubt, but there seems to have been no significant change in the character of Scotch for more than fifty years.

\section{More Tribology}

The Committee on Tribology which was announced by the Minister of Technology, Mr. Anthony Wedgwood Benn, in August (Nature, 210, 787; 1966) met for the first time last week. Mr. Benn has appointed Mr. H. Peter Jost as chairman; Mr. Jost was also the chairman of the working group set up by Lord Bowden, then of the Department of Education and Science, and is one of the strongest and most vocal supporters of the proposed "Institutes of Tribology".

No decision has yet been taken concerning the Institutes, but the committee will be considering the problem at its first meetings and hopes soon to make recommendations to the Ministry of Technology.

The committee will act as an advisory body to the Ministry of Technology and other organizations on ways of effecting savings in the area of "interacting surfaces in relative motion"; the working group estimated that industry could save $\$ 550$ million a year by taking tribological problems into consideration when designing equipment.

Mr. Benn emphasized that there must be both a general awareness of the problems and the specialists to deal with them. At present the University of Leeds offers M.Sc. and Ph.D. courses in lubrication, and the Imperial College of Science and Technology, London, is offering a series of three-week post-graduate courses in the subject; Bradford College of Technology is also starting a course in tribology this autumn. Some critics of the proposed institutes feel that they would cut across the interests of such established institutions, and others, including this journal (Nature, $210,338 ; 1966)$, have argued that the proposals are needlessly grandiose. It remains to be seen whether or not these arguments are valid and, indeed, whether the gains from better tribology are as great as the working group believes. The committee should, in any event, provide a useful forum to air the arguments and proposals on both sides. 